\title{
Identification of rice blast (Pyricularia) resistance genes in the breeding samples of rice
}

\author{
Nataliya Vozhzhova, ${ }^{1, *}$ Elena Krasnova ${ }^{1}$, and Elena Ionova ${ }^{1}$ \\ ${ }^{1}$ State Scientific Establishment "Agricultural research center "Donskoy”, 3, Nauchny gorodok str., \\ 347740, Zernograd, Rostov region, Russia
}

\begin{abstract}
The current paper has considered the challenge of breeding of rice lines adapted to the climatic conditions of the Southern Federal District of Russia by pyramiding a complex of Pi-1, Pi-2, Pi-33, Pi-ta and Pi-b rice blast resistance genes which is efficient in the southern part of Russia. The control of the resistance genes present in the breeding material was carried out using a marker-associated selection (MAS). The purpose of the current study was to identify the Pi-1, Pi-2, Pi-33, Pi-ta, and Pi-b rice blast resistance genes in the rice samples developed in the laboratory of rice breeding and seed production of the FSBSI "Agricultural Research Center "Donskoy" to identify valuable genotypes. The screening of 689 breeding samples of rice resulted in identification of the allelic state of the $\mathrm{Pi}-1, \mathrm{Pi}-2, \mathrm{Pi}-33$, Pi-ta and Pi-b rice blast resistance genes, and the genotypes with functional alleles of these genes and their combinations. There were identified 19 breeding samples of rice possessing a combination of 4 functional alleles of rice blast resistance genes in various combinations. The identified rice samples are valuable genetic material and are recommended to use as the sources of rice blast resistance in the breeding process.
\end{abstract}

\section{Introduction}

Rice is a hydrophilous plant, which is one of the main sources of nutrition for the world population. Rice productivity growth is impossible without striving against pathogens. One of the most dangerous rice diseases is a rice blast. Under its epiphytotic yield losses can range from 60 to $90 \%$. The grain yield obtained from the infected plants cannot be used for seed purposes because of its low quality [1].

The development of rice varieties that carry one or more rice blast resistance genes is currently one of the priority tasks for breeding [2].

The scientists from various rice-growing world countries are focused on the problem to transfer rice blast resistance genes from resistant varieties and thereby to evolve new resistant breeding material $[3,4]$.

*Corresponding author: nvozhzh@gmail.com 
About 100 rice blast resistance genes of rice have been identified in the world [5]. The Pi-1, Pi-2, Pi-33, Pi-ta, and Pi-b genes belong to the group of genes effectively opposing the disease in the southern part of Russia $[6,7,8]$. The problem of pyramiding these resistance genes in the varieties adapted to the conditions of the Southern Federal District of Russia has been solved in the laboratory of rice breeding and seed production at the FSBSI "Agricultural Research Center "Donskoy" for several years [9].

To breed the rice varieties resistant to rice blast it is important to control the allelic state of the donor genes transferred into the hybrid progeny, i.e. to identify both functional and non-functional alleles. In this regard, the method of marker-associated selection (MAS), which can accelerate the process of obtaining new varieties resistant to rice blast, is of great importance.

The purpose of the current study was to identify the efficient Pi-1, Pi-2, Pi-33, Pi-ta, and $\mathrm{Pi}-\mathrm{b}$ rice blast $\mathrm{s}$ resistance genes in the rice samples developed in the FSBSI "Agricultural Research Center "Donskoy" for identification of valuable genotypes with these pyramided genes.

\section{Materials and Methods}

The objects of the current study were 689 breeding samples of rice $\left(\mathrm{F}_{5}\right)$ developed in the laboratory of rice breeding and seed production at the FSBSI "Agricultural Research Center "Donskoy". The samples were estimated on the presence of Pi-1, Pi-2, Pi-33, Pi-ta, and Pi-b rice blast $\mathrm{s}$ resistance genes according to the specially developed protocols $[7,10,11]$.

DNA was extracted using 'DNA-Extran-3' kits (Syntol, Russia) according to the CTAB method. The polymerase chain reaction (PCR) was carried out in the amplifiers 'Applied Biosystem 2720' and 'Bio-Rad T-100'. The amplicons were separated by electrophoresis on $8 \%$ polyacrylamide gels in a Bio-Rad Mini-Protean Tetra Cell chamber (Bio-Rad, USA) and on $2 \%$ agarose gels in a SE-2 chamber (Helicon, Russia). Then, the gels were stained in a $1 \%$ solution of ethidium bromide. The study results were detected with a Bio-Rad GelDoc $\mathrm{XR}+$ instrument. The obtained electrophoregrams were analyzed by a Bio-Rad Image Lab 6.0 software.

The varieties 'C104-LAC' (a Pi-1 and Pi-33 gene donor), 'C101-A-51' (a Pi-2 gene donor), 'IR36' (a Pi-ta gene donor), 'BL-1' (a Pi-b gene donor), 'Novator' and 'Boyarin' (as a control of non-functional alleles) were used as the control parental forms.

To estimate the amplicons' size on agarose and polyacrylamide gels there were used the molecular weight markers Thermo Scientific GeneRuler 50 bp (50-1000 bp) and Evrogen 50+ bp DNA Ladder (50-700 bp), respectively.

\section{Results}

The screening of the 689 breeding samples of rice $\mathrm{F}_{5}$ developed in the laboratory of rice breeding and seed production at the FSBSI "Agricultural Research Center "Donskoy" by $\mathrm{Pi}-1$, Pi-2, Pi-33, Pi-ta and Pi-b rice blast resistance genes resulted in identification of a number of working polyacrylamide and agarose gels and their electrophoregrams.

An example of an electrophoregram of the products amplified on a polyacrylamide gel is shown in Figure 1. 


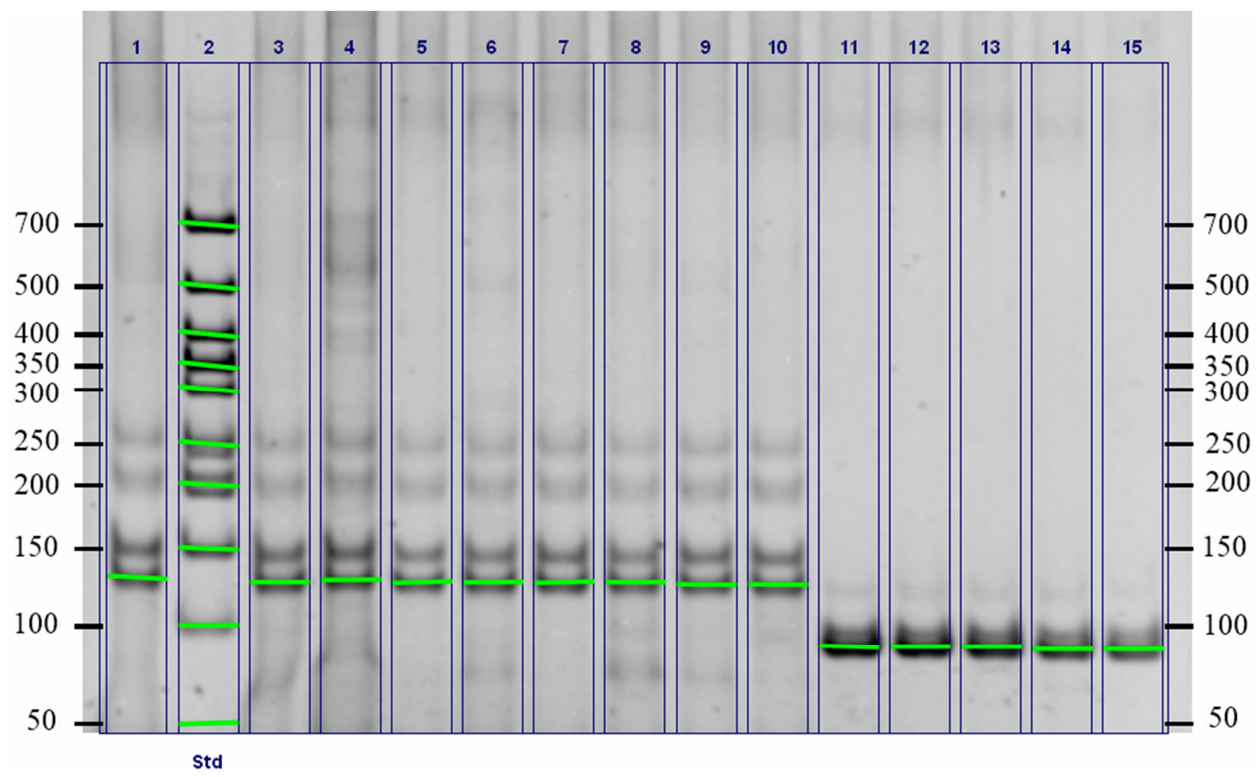

Fig. 1. The fragment of an electrophoregram of the screening of the rice samples with the Pi-33 rice blast resistance gene on a polyacrylamide gel: 1 - the variety 'Boyarin' (a control of the recessive allele); 2 - Molecular weight marker 50+ bp DNA Ladder Evrogen (50-700 bp); 3 - the sample ' $1889 / 1$ '; 4 - the sample ' $1889 / 2$ '; 5 - the sample ' $1889 / 3$ '; 6 - the sample ' $1889 / 4$ '; 7 - the sample ' $1890 / 1$ '; 8 - the sample ' $1890 / 2$ '; 9 - the sample ' $1890 / 3$ '; 10 - the sample '1890/4'; 11 - the sample ' $1892 / 1$ '; 12 - the sample ' $1892 / 2$ '; 13 - the sample '1892/3'; 14 - the sample '1892/4'; 15 - the sample 'C104-LAC' (a Pi-33 gene donor, a positive control).

The size of amplified fragments in the rice samples was compared with amplicons of the control parental varieties.

In Figure 1 the amplicons of the samples '1892/1', '1892/2', '1892/3' and '1892/4' are in the expected area and they comprise 95 nucleotide pairs (as the variety 'C104-LAC' being a Pi-33 gene donor). Therefore, these samples have a functional Pi-33 rice blast resistance gene.

The samples '1889/1', '1889/2', '1889/3', '1889/4', '1890/1', '1890/2', '1890/3' and ' $1890 / 4$ ' have a non-functional allele of the pi-33 gene, since the amplicons detected in them are similar to that in the non-functional control allele of the variety 'Boyarin'.

The other rice blast resistance genes studied in this work were identified in the same way.

The allelic state of the Pi-1, Pi-2, Pi-33, and Pi-b genes was similarly distributed in the studied population of rice samples, in contrast to the allelic state distribution of the Pi-ta gene.

The distribution of rice samples according to the allelic state of the Pi-1, Pi-2, Pi-33, Pita and $\mathrm{Pi}-\mathrm{b}$ rice blast resistance genes is shown in Figure 2. 


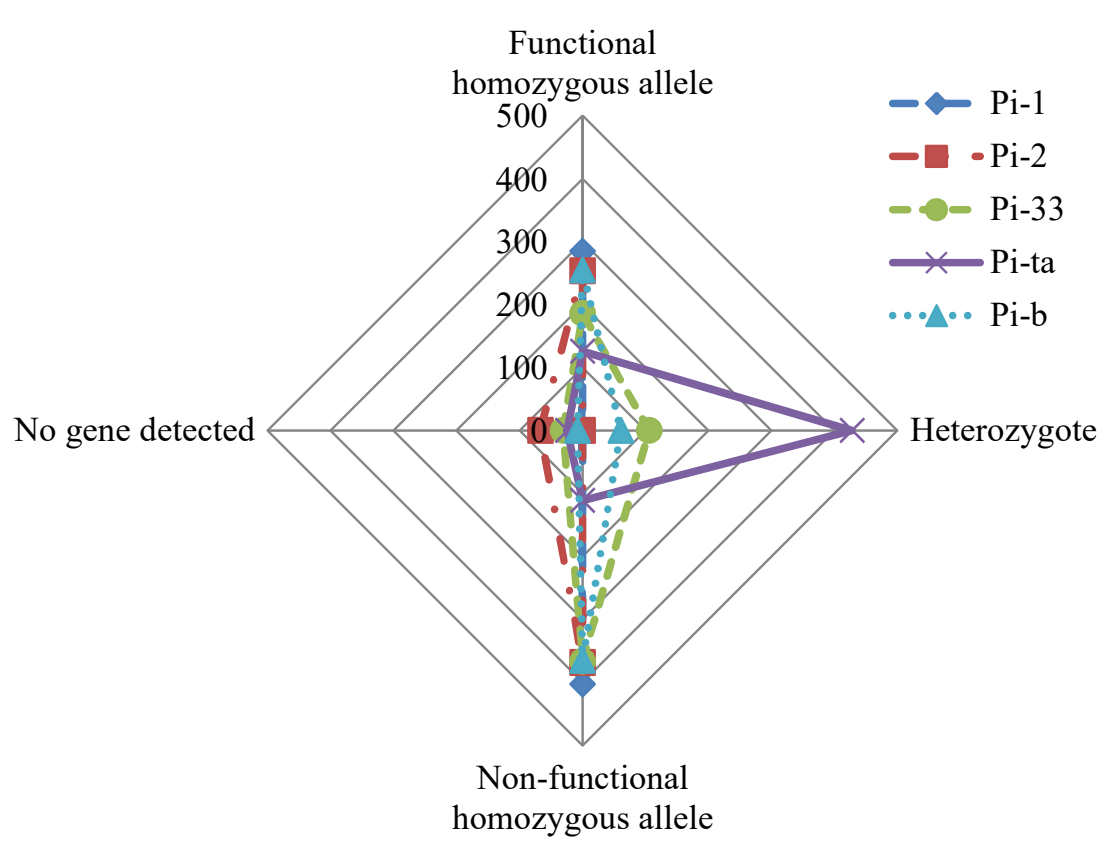

Fig. 2. Allelic states of the Pi-1, Pi-2, Pi-33, Pi-ta and Pi-b rice blast resistance genes in the breeding samples of rice.

The screening of the 689 rice samples F5 resulted in identification of the rice samples with the functional alleles of the rice blast s resistance genes, as follows Pi-1 (285 pcs.), Pi2 (254 pcs.), Pi-33 (186 pcs.), Pi-ta (126 pcs.) and Pi-b (255 pcs.). There was identified a heterozygous allelic state in the Pi-33 gene (106 pcs.), Pi-ta gene (428 pcs.) and Pi-b gene (61 pcs.). There was no heterozygous allelic state in the Pi-1 and Pi-2 genes.

There were identified nonfunctional alleles of $\mathrm{Pi}-1, \mathrm{Pi}-2, \mathrm{Pi}-33$, Pi-ta and $\mathrm{Pi}-\mathrm{b}$ rice blast resistance genes, namely Pi-1 (403 pcs.), Pi-2 (368 pcs.), Pi-33 (366 pcs.), Pi-ta (111 pcs.) and Pi-b (365 pcs.)

There were no identified rice blast resistance genes in some rice samples: Pi-1 (1 pc.), Pi-2 (67 pcs.), Pi-33 (31 pcs.), Pi-ta (24 pcs.) and Pi-b (8 pcs.). There was no amplified DNA on agarose and polyacrylamide gels.

The lack of amplification in a large number of rice samples may indicate significant variability in their genotype of the microsatellite sequence which the molecular marker was developed for.

The data obtained in the course of the current study of rice samples were introduced into the database. The analysis resulted in the identification of the samples that carried the combinations of several rice blast resistance genes.

There were identified $11.32 \%$ (78 pieces) of the rice samples which contained no one studied gene (Fig. 3). 


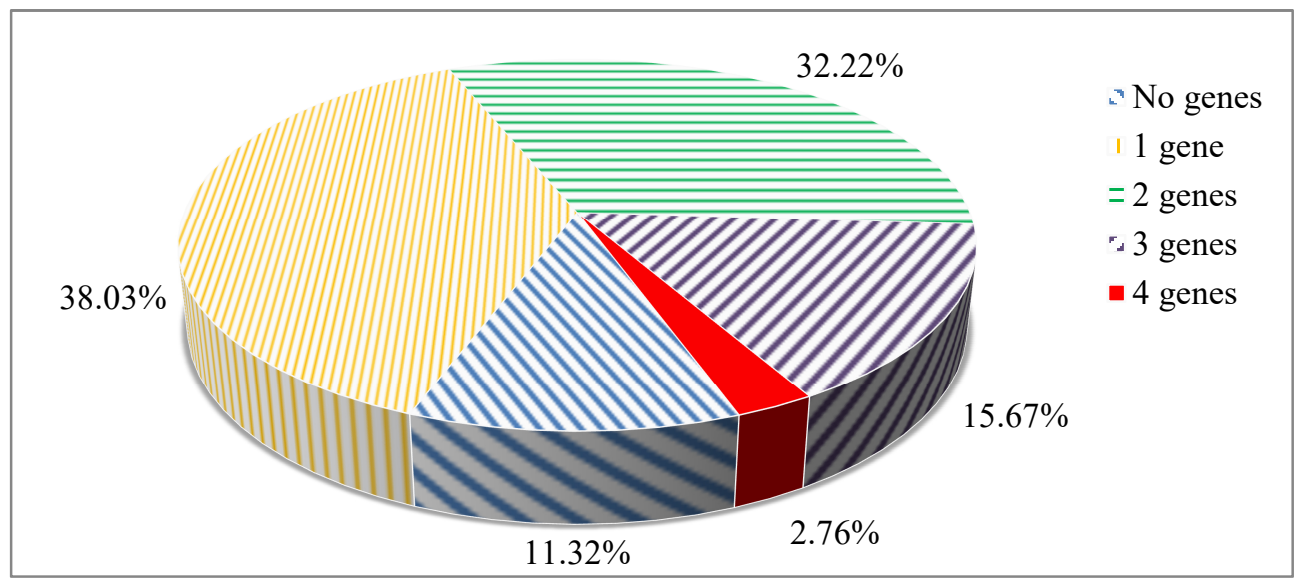

Fig. 3. Distribution of rice samples according to the number of the combined rice blast resistance genes.

There were identified $38.03 \%$ (262 pcs.) of the rice samples which contained one rice blast resistance gene, and $32.22 \%$ (222 pcs.) of the rice samples which contained a variously combined two rice blast resistance genes.

There were identified $15.67 \%$ (108 pcs.) of the rice samples which contained a combination of three rice blast resistance genes, and 2.76\% (19 pcs.) of the rice samples which contained a variously combined four rice blast resistance genes.

The rice samples with the combinations three and four rice blast resistance genes are shown in Table 1.

Table 1. Identified rice samples with several rice blast resistance genes.

\begin{tabular}{|c|c|c|}
\hline $\begin{array}{c}\text { Combination } \\
\text { of resistance } \\
\text { genes }\end{array}$ & $\begin{array}{c}\text { Number } \\
\text { of } \\
\text { samples }\end{array}$ & Name of samples \\
\hline $\mathrm{Pi} 1+2+\mathrm{b}$ & 13 & $\begin{array}{c}1446 / 1,1446 / 2,1446 / 4,1451 / 4,1722 / 4,1725 / 1,1725 / 2 \\
1843 / 4,1946 / 2,1946 / 3,1946 / 4,1958 / 3,2061 / 1\end{array}$ \\
\hline $\mathrm{Pi} 1+2+33$ & 15 & $\begin{array}{c}1693 / 2,1693 / 3,1693 / 4,1694 / 1,1694 / 2,1694 / 3,1694 / 4, \\
1696 / 3,1704 / 3,1704 / 4,1712 / 1,1892 / 1,1892 / 2,1892 / 3,1950 / 1\end{array}$ \\
\hline Pi1+33+ta & 1 & $1836 / 2$ \\
\hline Pi1 $+33+b$ & 26 & $\begin{array}{c}1703 / 2,1703 / 3,1703 / 4,1709 / 2,1709 / 3,1710 / 1,1710 / 2 \\
1710 / 3,1768 / 2,1768 / 3,1774 / 1,1774 / 2,1774 / 3,1774 / 4, \\
1778 / 3,1778 / 4,1781 / 1,1789 / 3,1790 / 1,1790 / 2,1790 / 3 \\
1790 / 4,1791 / 2,1791 / 3,1846 / 2,1862 / 2\end{array}$ \\
\hline $\mathrm{Pi} 1+\mathrm{ta}+\mathrm{b}$ & 13 & $\begin{array}{c}1451 / 3,1618 / 1,1621 / 1,1621 / 2,1624 / 2,1741 / 4,1742 / 1 \\
1744 / 1,1747 / 3,1753 / 4,1754 / 1,1754 / 3,1765 / 1\end{array}$ \\
\hline $\mathrm{Pi} 2+\mathrm{ta}+\mathrm{b}$ & 12 & $\begin{array}{c}1737 / 1,1737 / 3,1737 / 4,1738 / 4,1741 / 2,1745 / 1,1751 / 3 \\
1754 / 4,1756 / 2,1757 / 1,1758 / 2,1758 / 3\end{array}$ \\
\hline Pi $1+2+$ ta & 3 & $1751 / 1,1756 / 3,1845 / 4$ \\
\hline $\mathrm{Pi} 33+\mathrm{ta}+\mathrm{b}$ & 1 & $1768 / 4$ \\
\hline $\mathrm{Pi} 2+33+\mathrm{b}$ & 24 & $\begin{array}{c}1776 / 1,1782 / 1,1782 / 4,1783 / 1,1783 / 2,1783 / 3,1786 / 1, \\
1786 / 3,1786 / 4,1788 / 1,1788 / 2,1788 / 3,1793 / 4,1795 / 1, \\
1795 / 2,1795 / 3,1795 / 4,1842 / 2,2082 / 1,2082 / 2,2082 / 3, \\
2083 / 1,2083 / 2,2083 / 3\end{array}$ \\
\hline Pi1 $+2+33+b$ & 9 & $\begin{array}{c}1703 / 1,1783 / 4,1786 / 2,1789 / 1,1791 / 1,1791 / 4,1793 / 1 \\
1793 / 2,1793 / 3\end{array}$ \\
\hline Pi1+2+ta+b & 8 & $1743 / 3,1745 / 2,1745 / 3,1745 / 4,1748 / 1,1748 / 2,1748 / 4,1756 / 4$ \\
\hline Pi1+33+ta+b & 2 & $1846 / 1,1846 / 3$ \\
\hline
\end{tabular}


The predominant combination of rice blast resistance genes in our study was Pi1+Pi33+Pi-b (26 samples) and Pi2+Pi33+Pi-b (24 samples).

The rarest combination of genes for resistance to the rice blast was Pi1+Pi33+Pi-ta and Pi33+Pi-ta+Pi-b. One sample was identified with each of these combinations.

Nine rice samples had functional gene alleles Pi1, Pi2, Pi33 and Pi-b. Eight rice samples identified functional gene alleles Pi1, Pi2, Pi-ta and Pi-b. Two rice samples identified functional gene alleles Pi1, Pi33, Pi-ta and Pi-b.

We recommend to use the identified rice samples with several rice blast resistance genes in the breeding process.

\section{References}

1. A.H.M.M. Haque, F.A. Elazegui, M.A. Taher Mia, M.M. Kamal, M. Manjurul Haque, African Journal of Agricultural Research 7(26), 3819-3827 (2012) doi: 10.5897/AJAR12.541

2. E.V. Dubina, Zh.M. Mukhina, E.M. Haritonov, V.N. Shilovskij, E.S. Harchenko, L.V. Esaulova, N.N. Korkina, E.P. Maksimenko, I.B. Nikitina, Russ. J. Genet. 51, 752-756 (2015) https://doi.org/10.1134/S1022795415060058

3. S. Ashkani, M.Y. Rafii, M. Shabanimofrad, G. Miah, M. Sahebi, P. Azizi, F.A. Tanweer, M.S. Akhtar, A. Nasehi, Frontiers in plant science 6, 886 (2015) doi: 10.3389/fpls.2015.00886

4. Y. Wu, N. Xiao, Y. Chen, L. Yu, C. Pan, Y. Li, X. Zhang, N. Huang, H. Ji, Z. Dai, X. Chen, A. Li, Rice (New York) 12(1), 11 (2019) doi: 10.1186/s12284-019-0264-3

5. D. Srivastava, M. Shamim, M. Kumar, A. Mishra, P. Pandey, D. Kumar, P. Yadav, M.H. Siddiqui, K.N. Singh, Rice Science 24(6), 299-321 (2017) doi: 10.1016/j.rsci.2017.08.001

6. P.I. Kostylev, E.V. Krasnova, A.A. Redkin, Yu.P. Kalievskaya, Plant genetics, genomics, bioinformatics and biotechnology. Book of Abstracts (2017)

7. S. Fukuoka, R. Mizobuchi, N. Saka, I. Suprun, T. Matsumoto, K. Okuno, M. Yano, Theoretical and Applied Genetics 125, 551-559 (2012) doi: 10.1007/s00122-012-18524

8. E.V. Dubina, A.V. Alabushev, P.I. Kostylev, E.S. Kharchenko, M.G. Ruban, Yu.V. Aniskina, I.A. Shilov, N.S. Velishaeva, E.P. Maximenko, Yu.A. Makukha, Physiology and Molecular Biology of Plants 26, 289-303 (2020) doi: 10.1007/s12298-019-00737-6

9. P.I. Kostylev, 2nd Global Conference on Plant science and molecular biology. Theme: Accentuate innovations and emerging novel research in Plant sciences. Book of Abstracts, $\quad 32-33 \quad$ (2018) http://www.plant-science-biologyconferences.magnusgroup.org/uploads/pdfs/gpmb-2018-abstract-book.pdf

10. G. Miah, M.Y. Rafii, M.R. Ismail, A.B. Puteh, H.A. Rahim, Kh.N. Islam, M.A. Latif, Int. J. Mol. Sci. 14, 22499-22528 (2013) doi: 10.3390/ijms141122499

11. X. Wang, R. Fjellstrom, Y. Jia, W. G. Yan, M. H. Jia, B. E. Scheffler, D. Wu, Q. Shu, A. McClung, Plant Breeding 129, 491-501 (2010) doi: 10.1111/j.14390523.2009.01706.x 